\title{
Making sense of the 'is' of constitution
}

\author{
(Cómo dar cuenta del 'es' de constitución)
}

\author{
Ezequiel ZERBUDIs* \\ Universidad de Buenos Aires
}

\begin{abstract}
I consider a problem that arises in connection with (alleged) cases of coincident objects (such as a statue and the lump of clay it is made of) and that affects the two main accounts that have been given of such cases, namely, Pluralism (according to which statue and lump are distinct) and Monism (according to which they are one). The problem is that both views seem committed to accepting strained interpretations of some of the statements used to describe the situation. I consider Pickel's arguments against the Pluralist's strategy of interpreting 'is' as expressing constitution in sentences such as 'The statue is the lump of clay', and provide reasons for rejecting them—so as to vindicate, eventually, the Pluralist position.
\end{abstract}

KEYWORDS: material object, coincidence, constitution, polysemy, identity, predication.

RESUMEN: Considero un problema que surge en conexión con (supuestos) casos de objetos coincidentes (tal como el de una estatua y el trozo de arcilla del que está hecha) y que afecta a las dos explicaciones principales de tales casos, a saber, el Pluralismo (según el cual la estatua y el trozo de arcilla son distintos) y el Monismo (según el cual son un único objeto). El problema consiste en que ambas posiciones parecen tener que aceptar interpretaciones forzadas de algunos enunciados que pueden usarse para describir la situación. Considero los argumentos de Pickel en contra de la interpretación pluralista que interpreta 'es' como expresando la relación de constitución en oraciones del tipo de 'La estatua es el trozo de arcilla', y ofrezco razones para rechazarlos-lo que ayudaría a vindicar, eventualmente, la posición pluralista.

PALABRAS CLAVE: objeto material, coincidencia, constitución, polisemia, identidad, predicación.

* Correspondence to: Ezequiel Zerbudis. Instituto de Filosofía, Universidad de Buenos Aires, Puán 480 (1406) Ciudad de Buenos Aires, Argentina - ezerbu@yahoo.com - https://orcid.org/0000-0002-0093-372X

How to cite: Zerbudis, Ezequiel. (2021). "Making sense of the 'is' of constitution»; Theoria. An International Journal for Theory, History and Foundations of Science, 36(1), 25-47. (https://doi.org/10.1387/theoria.21232).

Received: 2019, November 08; Final version: 2020, August 11.

ISSN 0495-4548 - eISSN 2171-679X / (C) 2021 UPV/EHU

This article is distributed under the terms of the

Creative Commons Atribution 4.0 Internacional License 


\section{Introduction}

In what follows I consider a problem that arises for two competing accounts of situations that might be described as involving coincident objects. Typical examples of this kind of situation include the much discussed one of Goliath and Lumpl, that is, of a statue and the lump of clay it is made of (cf. Gibbard, 1975). There are two main and conflicting interpretations that could be given of what's going on in such cases: on the one hand, the Monists (or "one-thingers") claim that the statue and the corresponding lump are identical, that is, that there is only one thing in the situation described above; on the other hand, the Pluralists (or "multi-thingers") hold that the statue and the lump are not identical, so that we have (at least) two different things in the region that (say) the statue occupies. Arguments of different sorts have been wielded in favour of one or the other of these views, but in what follows I will be mainly concerned with arguments of a linguistic nature, based on the commitments that allegedly follow from the intuitive acceptance of some statements describing such situations.

Here is an argument that has been supposed to favour Pluralism. Its point of departure is our intuitive acceptance of statements such as (1) and (2):

(1) The lump of clay could survive being squashed.

(2) The statue could not survive being squashed.

Now, according to Leibniz's Law, if two things are numerically identical, then they will share all of their properties; so that, if there are things that do not share all of their properties, then they could not be the same. Now, given that (1) and (2) seem to show that the lump and the statue do differ in some of their properties (one of them has the property of being able to survive a squashing, while the other seems to lack this very same property), it would seem to follow that we have to accept the conclusion (3):

(3) The statue is not (identical to) the lump.

The statue and the lump are therefore two different, albeit coincident, material objects.

Monists, on the other hand, could draw our attention to the intuitive acceptability of statements such as (4)-(6):

(4) The statue is a lump of clay.

(5) The statue is the lump.

(6) Goliath is Lumpl.

And they might argue that it would follow from our acceptance of these statements that the statue and the lump in a situation such as the one described above are identical - given that, of course, 'is' in such statements is most naturally understood as expressing identity between the items described or named (this is certainly so in (5) and (6); and it has also been argued that, even if one were to think that 'is' in (4) is just a device of predication, it would still follow from (4) that the statue is identical to a lump of clay, given that it is identical to itself, which is (also) described as a lump of clay; cf. Pickel (2010, p. 197)).

In such a dialectical situation, it is only to be expected that one important aim of the argumentative strategy of both sides in the dispute should consist in providing acceptable readings of the statements on which the arguments of the opposite side are based. In this vein, Monists could try to show that some of the terms in sentences (1) and (2) appear 
there in contexts that require a shift in their interpretation - either because the relevant singular terms ('the statue', 'the lump') appear in opaque contexts in those sentences (in which case they would not refer to the same items in the premises and in the conclusion, so the argument would be invalid, because based on an equivocation), or because the relevant predicate ('to be squashed into a ball') might be taken to express different properties in the different premises (and so we would again have an equivocation). ${ }^{1}$ A natural response from the Pluralist side to the argument based on (4)-(6), on the other hand, might include the suggestion that 'is' should not be understood, in those statements, as either expressing, or implying, the identity between the statue and the coincident piece of clay, but rather as expressing a relation of constitution that holds between them: the idea would be that in statements (4)-(6) what 'is' expresses is not that a lump of clay is identical to a statue, but rather that the one constitutes (or is constituted by) the other. Such instances of 'is' would be instances of what Wiggins called the 'is' of constitution (cf. in particular Wiggins (1980, ch. 1) for a defence of this view).

Of course, both dialectical strategies are open to criticism. The Monist strategy has, indeed, been accused of incurring in "unmotivated semantics", as the shifts in interpretation allegedly affecting some of the terms do not appear to conform to paradigmatic examples and patterns of such phenomena in languages such as English (cf. Fine (2003) and the brief discussion in fn. 1 above). The defensive strategy we have considered on behalf of the Pluralist, on the other hand, has also come under attack recently. In particular, Bryan Pickel (2010) has argued that the supposition that 'is' in (4)-(6) expresses constitution (instead of identity) could (also) be characterized as a case of "unmotivated semantics", as this hypothesis, or so he argues, seems to conflict with the linguistic evidence available (Pickel also thinks, on the other hand, that the Monists' own semantic hypotheses are not unmotivated, so that they are indeed in a better position than the Pluralists, at least in so far as these linguistic arguments are concerned; but he does not really argue in favour of this view, so that we are not in a position to judge this claim). In what follows I argue that Pickel's arguments against the 'is' of constitution are unconvincing and that, therefore, as far as these linguistic arguments are concerned, the Pluralist view is still in good shape.

1 See Noonan (1993) for a presentation of a Monist argument of this kind (according to his view modal predicates are "Abelardian", namely, such that they may refer to different properties when applied to different terms), Fine (2003) for a discussion (and rejection) of this sort of defensive move from the Monist, and King (2006) for a (limited) defence of the Monist's strategy from Fine's attack. It is important to note that, even if King is right in his rejection of Fine's arguments, more would be needed to validate the Monist's view: King only succeeds in showing that some contexts like those involved in arguments of the form (1)-(3) might reasonably be taken to be opaque, and to give therefore rise to a referential shift, and that some predicates appearing in sentences such as (1) and (2) might be context sensitive, so as to ascribe different properties to (say) the statue and the lump of clay. But he himself admits that the reasons he provides for thinking so do not apply across the board, so that, in many cases, (the relevant instances of) the arguments would still go through (cf. King (2006, p. $1030 \mathrm{ff}$.) for such a conclusion regarding opacity and singular terms, (2006, pp. 1056-7) for predicates and their properties). 


\section{Pickel's argument}

\subsection{Pickel's general Strategy}

As I have already said, Pickel tries to show that the hypothesis that 'is' in sentences such as (4)-(6) behaves as what Wiggins has called the "is' of constitution" should be rejected. It is important to take into account, besides, that Pickel is interested in showing that this hypothesis is not acceptable according to the very same standards that the Pluralists made use of in arguing against the semantic hypotheses of the Monists - namely, because it is a semantic hypothesis that is in conflict with the empirical evidence, according to the standards accepted by current linguistic theories. What he tries to show, then, is that none of the criteria ordinarily used by linguists to detect the existence of different readings for some expressions back the hypothesis that 'is' might sometimes be interpreted as expressing constitution. ${ }^{2}$ More specifically, Pickel argues that, if there was an 'is' of constitution, that would require one of the following hypotheses to be the case:

(a) 'is' is ambiguous - or, more precisely, more ambiguous than usually recognized. The idea would be that, besides the two typically accepted readings, according to which 'is' may express either identity or predication, another reading should be added, namely, one according to which 'is' expresses constitution. ${ }^{3}$

(b) 'is' is context-sensitive. According to this hypothesis, 'is' would express different relations on different occasions - so that it might end up expressing constitution on some occasions.

(c) 'is' is an unspecific term. The idea would be that 'is' has a single meaning, but one which is broad enough, so that 'is' applies to pairs of terms in virtue of different relations holding between them (one among which would be that of constitution).

I find Pickel's arguments concerning (c) (2010, pp. 207-10) convincing enough, and I therefore agree with his conclusion that 'is' is not an unspecific term (in a sense to be discussed in a more detailed way below). In contrast, I find his discussion of hypotheses (a) and (b) flawed and unconvincing. In my discussion in what follows, I will mainly focus on (a), his treatment of the hypothesis according to which 'is' is ambiguous, and will also occasionally connect some of the points I make concerning this hypothesis to some of his claims concerning (b), which I shall also reject. This seems reasonable, as he himself connects both hypotheses, given that he considers the fact that an expression may receive different interpretations on different occasions as just (giving rise to) a specific case of ambiguity.

2 It is interesting to notice here that Pickel's arguments have also been accepted by philosophers with Pluralist leanings, such as Korman (2015, pp. 209-212).

3 It is also usually assumed that, besides the 'is' of identity and the 'is' of predication, the expression also has a further sense, namely, that it is sometimes just used to ascribe being, as when someone says that "Pegasus is", simpliciter (cf. for instance Quine (1948, p. 2 and passim)). I think this is correct, but I will set this other use of 'is' aside in what follows, as it is irrelevant to the discussion of whether 'is' may sometimes express constitution (for which some sort of complement seems required). 


\subsection{Pickel against 'is' as ambiguous}

According to Pickel, the Pluralist who tries to make room for an 'is' of constitution on the basis of an (alleged) ambiguity of 'is' should be committed to the idea of 'is' being (at least) three-way ambiguous, as between

- the 'is' of identity,

- the 'is' of predication (namely, the copula), and, finally

- the 'is' of constitution.

Let me just make clear at the outset that I think this way of dividing the different uses of 'is' is problematic, as it seems to conflate two different criteria we might use in this connection - one that takes into account the logico-syntactic, the other the semantic properties of the expressions. It seems to me, indeed, that when we speak of the 'is' of identity we do not only want to express that 'is' designates this specific relation, but also to indicate that it is a "relational" sort of 'is', one that makes a specific kind of contribution to the logical form of the sentences in which it appears - namely, that it is an 'is' that designates a (dyadic) relation, and that it correspondingly has two slots to be filled with singular terms; while, on the other hand, when we talk of the 'is' of predication we mainly mean that it combines with some adjectival or nominal phrase (i.e., with something equivalent to a general term) in order to build a predicate. ${ }^{4}$ Now, it is important to note that the alleged 'is' of constitution is not simply a third way of understanding 'is' along these other two, but that it actually consists in providing alternative ways of interpreting any of those two other 'is's, which are distinguished from one another from a formal point of view: in the case of a statement of the form ' $a=b$ ', ${ }^{5}$ as in (6) above, what the proponent of the 'is' of constitution says is that '=' should be understood as expressing, not the relation of identity between $a$ and $b$, but rather that $a$ either constitutes, or is constituted by, $b$. On the other hand, in the case of a sentence with the form ' $a$ is an $F$ ', where 'an $F$ ' is a noun phrase (as in (4) above), one thing that the proponent of the 'is' of constitution claims is that 'is' should not be interpreted there as expressing that $a$ has the property of being an $F$ itself, but that it has the property of being constituted by an $F$. This distinction may not seem particularly important at this stage of the argument, but I think it's useful to present it already here, as it will have a role to play in the way I organize my response to Pickel.

In any case, one of the main points Pickel wants to make is that, if the hypothesis (a) above (namely, the hypothesis that 'is' is ambiguous) is correct, then one should be able to detect the relevant ambiguities by applying to 'is', as it is used in examples such as (4)(6), some of the standard tests that linguists use for detecting ambiguities. But, he will contend, none of the tests ordinarily used to that purpose is able to detect any such ambigu-

4 The distinction between these two sorts of 'is' has a long tradition in analytic philosophy, going back at least to the work of Frege. Russell (1919, p. 172) offers a nice presentation of the distinction: "The is of 'Socrates is human' expresses the relation of subject and predicate; the is of 'Socrates is a man' expresses identity. It is a disgrace to the human race that it has chosen to employ the same word 'is' for these two entirely different ideas-a disgrace which a symbolic logical language of course remedies." On the other hand, I do not mean to imply that the notion of logical form is unproblematic; but I think the pre-theoretic grasp we may have of it is enough for present purposes.

5 I ignore here (and in what follows) the difference between inverted commas and corner quotes. 
ity. He thinks therefore that he is entitled to say, as he puts it in the title of his paper, that "there is no 'is' of constitution". I think he actually fails to show that this is the case. But before assessing his arguments, let us consider with some more detail what these are.

Pickel mainly uses two groups of tests for detecting ambiguities, the semantic and syntactic tests developed by Sadock and Zwicky (1975). ${ }^{6}$ Let's begin with the first of these.

Semantic tests purport to show that there is an ambiguity in some lexical item or syntactic construction by making apparent the different interpretations that could be given to them, as revealed in the intuitive truth (or some other semantic property) of statements in which they appear. Pickel mentions two main tests of this kind as relevant for his argument, the contradiction and redundancy tests.

The main idea of the contradiction test consists in taking some sentence form that one would naturally expect to give rise to contradictory utterances, such as ' $a$ is $F$ and $a$ is not $F$, and noticing that the existence of intuitively true instances of statements of this form could be seen as evidence that ' $F$ ' is an ambiguous term, as it would be natural to interpret ' $F$ ' in such cases as ascribing in the first clause a property to the subject different from the one that is being denied of it in the second one. Now, consider for instance (7) (cf. Pickel, 2010, p. 201):

(7) He decided on the boat, but didn't decide on the boat.

The fact that there is an acceptable (i.e., non-contradictory) reading of (7) would then show that there is an expression - in this case, presumably, 'on' - that is ambiguous. Indeed, it seems natural to interpret the two instances of 'on' as expressing something similar to 'about' or 'concerning' in one of the cases, and as expressing that the relevant person is located on the surface of the boat in the other. But now, Pickel says, it is not clear that (8) would (as clearly) have an acceptable reading, as the Pluralists' hypothesis would require:

*(8) The statue is a piece of clay, but it is not a piece of clay. ${ }^{7}$

The result would then be that the contradiction test does not reveal the alleged ambiguity in 'is'. ${ }^{8}$

6 These are Sadock and Zwicky's labels. Other authors name what are essentially the same groups of tests in some other ways. For instance, in another classic paper on these topics, Geeraerts (1993, p. 229) calls the first group 'truth-conditional tests', and the second one 'linguistic tests'.

7 It should be noticed that Pickel typically has a sentence such as (4), not one like (5) or (6), as his main discussion target. I follow him and do the same in this section, as I'm here only trying to present his views. I'll pay more attention to cases such as (5) and (6) later, when I present my own views on the topic.

8 It should be noticed here that, strictly speaking, the existence of non-contradictory instances of a sentence form such as that of (7) or (8) provides evidence for the ambiguity of (at least) one of the terms involved (and something similar happens, mutatis mutandis, with the non-redundant or nonzeugmatic character of some instances according to some of the tests we discuss later). Now, Pickel uses these tests here to argue for the non-ambiguity of a term on the basis of his being unable to find non-contradictory instances involving the term, which would require assuming that, if a term was indeed ambiguous, that ambiguity should become apparent, in one way or another, in some of the sentence forms used to test for ambiguity (I think this assumption has not been adequately justified, but I'll take it for granted in what follows for the sake of argument). That is: if there aren't any non-contradictory instances of sentences of the form of (7) or (8) involving a certain term, that can be taken as 
The main idea behind the redundancy test, on the other hand, is very similar. We select first a sentence form that we would naturally expect to give rise to redundant utterances, such as ' $a$ is $F$ and $a$ is $F$ '. Now, if we find that such a sentence type may sometimes be used to make a non-redundant utterance, it seems natural to suppose that this is so because ' $F$ ' designates different properties in its two appearances, which would imply that it is ambiguous. Again, 'on' in (9) could provide a good example:

(9) He decided on the boat, and on the boat.

Now, it would seem that an attempt to apply this test to 'is' (as it is used in (4)) gives the wrong result, as (10) is intuitively redundant:

*(10) The statue is a piece of clay, and it is a piece of clay.

We then get the same result as above in connection with the alleged 'is' of constitution.

As for the syntactic tests, they aim to make apparent the different interpretations that some terms (or constructions) might receive, on the basis of the intuitive acceptability (or otherwise) of some particular syntactic combinations. Among these, Pickel discusses the coordination and the ellipsis tests.

The coordination test is based on the observation that there are some contexts that, even though they combine felicitously with some terms taken individually, do not combine felicitously with the conjunction of those very same terms (because the sentence so formed is perceived as zeugmatic). This phenomenon is then supposed to test for ambiguity because the best explanation that could be given of these results is that (some expression(s) or construction(s) in) the relevant contexts receive different interpretations when combined with different terms. A good example of this phenomenon is provided by sentences (11)(14) (cf. Pickel, 2010, p. 202):

(11) The fire lit his way.

(12) The fire lit his cigarette.

?(13) The fire lit his way and his cigarette.

(14) The fire lit his way and his map.

The idea would then be that what explains the acceptability of (11) and (12), but the unacceptability of (13), is that the context 'the fire lit...' (in particular, the expression 'lit', and the verb 'to light' from which it derives) is ambiguous: it is used in one sense in (11) and in a different sense in (12), and that explains why (13) is problematic, as that utterance requires different readings of one and the same use (contrary to what happens in (14), where the very same reading of 'lit' combines perfectly well with both coordinated complements). Pickel notes that something very much like this takes place in connection with the ambi-

evidence that the relevant term is unambiguous. Now, such general negative claims are, of course, hard to assess. Pickel seems to be addressing this problem by making a further assumption, namely, that if a view concerning the semantics of a term makes us expect it to behave in some specific way (for instance, to deploy different senses in some circumstances), then the fact that it does not behave in that way would be evidence enough that that view about the term is wrong. Something like this seems to be at work in his discussion of (8): the Pluralist seems committed to the idea that it should be possible to read 'is' as expressing constitution as well as identity in a sentence of that kind, but then its contradictory character would show us that that view is wrong. 
guity between the 'is' of predication and the 'is' of identity, as the zeugmatic effect in (17) makes clear (whereas (15) and (16) are both acceptable):

(15) He is Mark Twain and Samuel Clemens.

(16) He is witty and clever.

?(17) He is witty and Samuel Clemens.

So, one would expect that, if 'is' was indeed ambiguous between, say, predicative and "constitutional" readings, this would give rise to zeugmatic effects when 'is' is combined with coordinated complements demanding these two different readings. In the following examples, (18) is a clear case of a predicative use of 'is', while (19) would seem to require a reading according to which it designates constitution (if 'is' ever does). But, contrary to what happened with (17), we find that (20) seems perfectly acceptable:

(18) This cup is shiny.

(19) This cup is a piece of metal.

(20) This cup is shiny and a piece of metal.

The fact that (20) is not zeugmatic (or, at least, not as zeugmatic as (17)) seems to show that we have no reason to suppose that 'is' is ambiguous in (18)-(20).?

Finally, the ellipsis test is based on the fact that it seems acceptable to delete some recurring terms, in order to avoid redundancy, when those terms receive the same interpretation (but not otherwise). So, for instance, while (21) seems acceptable, (22) does not:

(21) John wrote a novel; Harry, a poem.

?(22) The fire lit my way; the lighter, John's cigarette.

The difference between both examples seems to depend, of course, on the fact that, while 'to write' is used in the same sense in both clauses in (21), 'to light' is used in two distinct senses in the two clauses of (22) - as it is semantically equivalent to 'to illuminate' in the first one, but to 'to set fire to' in the second.

Now, in connection with the alleged ambiguity of 'is', Pickel notices that 'is' seems to behave more like the unambiguous 'to write' than like the ambiguous 'to light', as (23) seems perfectly acceptable:

(23) This cup is shiny; this other one, a piece of metal.

Thus, here, as with the other tests, 'is' does not behave as an ambiguous term.

9 Let me just record here that, to me (and, indeed, to some other people that heard or read this paper), (20) does sound at least a bit zeugmatic, as also do some of the other examples discussed by Pickel (for instance, 'The piece of metal was shiny, and a nice cup' (2010, p. 202)). As I suspect I might be here being influenced, in having these intuitions, by the theoretic views I accept, I won't assign in what follows any force to this point. On the other hand, we see here again at work the methodological assumption mentioned at the end of the previous footnote: Pickel supposes that (20) should be zeugmatic if 'is' was indeed ambiguous (between a predicative sense, as in (18), and one in which it expresses constitution, as it allegedly does in (19)), and infers, in consequence, its non-ambiguous character from the non-zeugmatic character of the statement. 


\subsection{Pickel against 'is' as Context-Sensitive}

Another of the hypotheses that Pickel considers on behalf of the Pluralist is that 'is' should be taken as context-sensitive, that is, as an expression that may receive different specific readings in different contexts, not in virtue of some sort of conventional, lexical ambiguity, but in virtue of the term being such as to require "completion" by (some aspect of) the occasion of utterance - either because it is underdetermined or (covertly) indexical. In any case, Pickel deals with this hypothesis as if it was just a variation of the ambiguity hypothesis: as the proposal implies that some term or construction might occasionally be interpreted in different ways, he claims that such variability should eventually be detected by some of the ambiguity tests. And he backs this assumption by considering an example in which this seems to be the case. So, for instance, it has been noticed that the possessive construction may be used to express not only possession but also, occasionally, some other relations obtaining between a person and an object. 'John's car', for example, is most often understood as referring to a car owned by John; but in some circumstances, for instance, if John is an employee in a car washing station, 'John's car' may be used to refer to the car that John is washing at the moment, or has been asked to wash; or, if John is a taxi driver, 'John's car' may be used to refer not to a car he owns, but to the one he usually (or occasionally) drives. Now, Pickel says, in connection with a situation in which many people are washing cars, that the following exchange would be acceptable:

(24) a. Is the car which John is washing the one he owns?

b. No, John's car is not John's car.

This would imply that the possessive construction passes one of the tests for ambiguity (in this case, the contradiction test), which would in turn be an indication that the expression is one that receives different interpretations. As he puts it:

Even though some forms of context sensitivity can be more difficult to detect than are ambiguities, it should not resist all tests for multiple readings. If a construction such as the possessive really generates different readings in different contexts, then one should be able to construct a single context [such as in (24)] in which these readings are made explicit. (2010, p. 206)

Even if we agree that (24) is acceptable in the envisaged context, it is not clear to me that the generalization Pickel is trying to establish on that basis is justified. On the contrary, it just doesn't seem to follow, from the fact that an expression may receive different interpretations in different contexts, that in general one should be able to build a single context in which both interpretations are available (most obviously: from the fact that 'I'm tired' may be used to ascribe the property of being tired to different people in different contexts it doesn't follow that we may build a single context in which it is used to ascribe that property to different people).

Be that as it may, given that Pickel treats cases of this kind just as special cases of ambiguity, and that I don't think it is particularly important which is the source of the terms' ability to receive different interpretations, as I hope to make clear in what follows, I'll take it that these sorts of cases will also be covered in the main discussion below. 


\section{Assessing Pickel's arguments}

\subsection{InTRODUCING POLYSEMY}

Thus far, then, we have reviewed a significant portion of the arguments that Pickel directs against the hypothesis that 'is' designates constitution in sentences such as (4)-(6). I turn now to an assessment of them and, in particular, to the assessment of his use of the ambiguity tests to back his view. In connection with this, I won't reject any of the particular results he obtains from the application of the tests to the specific sentences he discusses. I will dispute, though, the significance he ascribes to our inability to detect different readings of 'is' in those cases.

Now, a first point to note in this connection is that, when Sadock and Zwicky discuss the different tests for detecting ambiguities, they explicitly state that their tests purport "to distinguish ambiguity from lack of specification" (1975, p. 1) among terms and syntactic constructions that may be used to refer to, or describe, different situations. They clarify later that by 'ambiguity' they mean "several underlying syntactic (or semantic) representations" that would account for the behaviour of some such expressions, while with 'lack of specification' they characterize cases where what we find is "a single representation corresponding to different states of affairs" (p. 2). Some examples might help clarify this distinction.

Cases of ambiguity should be relatively straightforward, given our discussion above; (25) should then be an uncontroversial (and rather boring) example:

(25) He went to the bank

where, of course, 'bank' may receive the interpretations 'river bank' or 'financial institution'. On the other hand, (26) would be a clear example of lack of specification or unspecificity, as I've already called it:

(26) Yesterday I talked to John's brother-in-law

where someone may be John's brother-in-law either by being his wife's (or his husband's) brother or his sister's (or his brother's) husband.

Now, I'd like to suggest that ambiguity and unspecificity might be considered as species of a more general phenomenon, which I propose to call (for lack of a better name) 'referential latitude', namely, the phenomenon that consists in a certain linguistic form being semantically connected with different aspects of reality - that is, with aspects of reality that, for whatever reason, we tend to differentiate further. ${ }^{10}$ Now, ambiguous and unspecific terms realize this general idea in different ways. So, a case of ambiguity, like (25), is a case where, for instance, a single term or word form ('bank', in this case) is connected to two different "aspects" of reality by means of two different conventions - that is, by means of conventions that, it seems reasonable to assume, speakers perceive as independent from one

10 My talk about 'aspects of reality' is deliberately vague here, and could be understood as referring either to the terms' extensions or (in the case of predicative expressions) to the properties they may be taken to express; I take it that this is innocuous, as I shall assume, in any case, that they are related to one another in the usual way (namely, so that something belongs to the extension of a predicative expression if and only if it instantiates one of the (possibly many) properties semantically associated with it). 
another. ${ }^{11}$ On the other hand, 'brother-in-law' seems to be connected, by means of a single semantic rule, to a rather broad section of reality, one that we find natural to differentiate further.

Now, it seems clear to me that these two relatively well defined groups of terms do not exhaust the whole class of terms exhibiting what I called referential latitude. ${ }^{12}$ Indeed, philosophers of language, linguists and psycholinguists have for some time now studied a class of terms that we may place between the two poles of ambiguous and unspecific terms, namely, that of so called "polysemous words". These are words that have "various different, but related, meanings" (Vicente, 2018, pp. 951-2; my emphasis). ${ }^{13}$ As examples of polysemous words we find, interestingly, some examples that Quine (1960, pp. $129 \mathrm{ff}$.) had described as instances of 'generality', and that Sadock and Zwicky understood (wrongly, in my view) as cases of unspecificity. Consider, for instance, the following two pairs of sentences:

(27) That was a hard remark.

(28) This is a very hard rock.

(29) This rope is elastic.

(30) Our plans are elastic.

It seems to me clear enough that, for instance, what 'hard' says of a remark in (27) is very different from what it says of a rock in (28), so that it would be natural to say that 'hard' receives different readings, or that it expresses different "senses" (as they are usually called), in those two examples, even though we may also concede that these two senses are not completely unrelated (that is, the term would not be ambiguous as characterized above). And again, 'elastic' does not seem to ascribe the same to ropes as to plans. This perceived connection between the two senses of each of these words has at least two dimensions: on the one hand, it seems that there are some elements in common between those two senses, that is, that the characteristics they ascribe to the items belonging to their extensions overlap to some extent (in the case of 'hard', for instance, the common element might be something like apt for causing damage, or something along these lines); on the other hand, it seems natural to suppose either that one of the senses derived from the other one, or that both of them derived from some common source (in the present examples and many similar ones, it seems natural to suppose that this could have happened through some sort of metaphoric process).

I think it might be useful to give some more examples to improve our grasp of the phenomenon. So, for instance, 'brilliant', when applied to an idea, may be said to express

${ }^{11}$ I won't take a stand here on whether, and how, ambiguous terms (understood as just characterized) should be distinguished from so called 'homonyms', namely, from pairs of exactly similar forms taken as two distinct lexical items, each associated with its own, separate, semantic rule.

12 This is probably connected to the fact that the usual tests in this area only distinguish between these two classes, which in turn seems to depend from the fact that they were primarily intended to detect syntactic, rather than lexical, ambiguities.

13 Vicente contrasts, in a similar way, polysemous terms with homonymous terms (forms with two or several unrelated meanings), on the one hand, and with monosemous terms (which have only one meaning, with might then be unspecific), on the other. Cf. also Falkum and Vicente (2015) for an overview of different treatments of polysemy, and Nunberg (1979) for an early, influential discussion. 
something different (though related) from what it expresses when it is applied to a metallic surface. Or 'school' may be used to talk of an institution, or of a group or people, or of a building, all of which are, nonetheless, related to one another in a clear way. And something similar applies to 'book': it may be used to refer to a certain abstract entity, a text, or to a concrete physical object, one embodying it.

Now, it is certainly the case that the class of polysemous terms is vague and diverse-as Nunberg put it, "Polysemy' is a gradient phenomenon" (1979, p. 147). There are different dimensions of indeterminacy and variability among such terms, among which the following could be mentioned:

1. It might not be clear how to distinguish the different senses a word may havefor instance, how dissimilar they should be from one another to count as different senses and, in connection with this, whether and to what extent we could determine how many different senses a term has.

2. There are also differences concerning the extent to which the various senses of an expression have become, or not, conventionalized, that is, connected to the terms through distinct conventions; and also, in connection with this, it may be unclear whether what a term expresses in a particular occasion should be accounted for in semantic or pragmatic terms-and, correspondingly, it may also be unclear to what extent the interpretation an expression receives depends on features of the occasion of use.

3. Also, different models of how the meanings of lexical words are structured and stored could be offered - for instance, they might be taken to be overspecific, so that their occasional interpretations are obtained by selecting some aspects of their standing meaning, and they might also be taken to be underdetermined, so that particular interpretations are obtained by completing a core, thin meaning, typically by taking into account some relevant aspect of the occasion of use (again, it has also been suggested that some terms behave in one way and others in the other; cf. Vicente (2018) for a "pluralist" view of this kind).

4. Finally, there may be different kinds of polysemy, exhibiting different sorts of relation between their senses - the polysemy may be regular or irregular, based on metonymic or metaphorical processes, etc.

It would be way outside the scope of the present paper to try to explore in a detailed way any of these issues, interesting as they are in themselves. In what follows I'll rather focus on just a couple of points that are directly relevant for answering Pickel's argument concerning the 'is' of constitution:

(i) I'll try to show that the recognition of the class of polysemous terms is important for evaluating the significance of the ambiguity tests for the specific task of deciding whether a term may receive or not different interpretations, because polysemous words often obtain mixed results with those tests (and may even fail most of them).

(ii) I'll try to provide some evidence that (relational) 'is' is indeed a polysemous term, that is, one that expresses different (though related) relations in different contexts, and that there are good reasons to suppose that constitution could be one of these.

I'll consider these two issues in turn in the following sections. 


\subsection{Polysemy and the ambiguity tests}

As we already suggested, adjectives like 'hard' or 'elastic' are naturally taken to be polysemous: they seem to express different, though related, senses in their different uses (as in $(27) /(28)$ and $(29) /(30)$ above). But, interestingly enough, some such terms (such as, for instance, 'elastic') seem to fail all of the tests for ambiguity Pickel discusses.

Let's begin by considering how some of these terms behave as regards the semantic tests. In relation to the contradiction test, it seems that (31) and (32), for instance, do appear to be contradictory (and the same seems to happen with any other similar example involving 'elastic' that comes to mind), so that 'elastic' would have to be classified as non-ambiguous according to this test:

(31) This rope is elastic, but it is not elastic.

(32) Our plans are elastic, but they are not elastic. ${ }^{14}$

The same seems to follow from an application of the redundancy test, as it seems difficult to find a non-redundant reading of (33):

(33) This rope is elastic, and it is elastic.

What seems to be happening in cases such as (31) and (32) is that 'elastic' receives different specific interpretations according to the different nouns with which it combines in each case (it is (arguably) understood in one way when (and because) it is applied to 'rope' but in another way when (because) it is applied to 'plan'). ${ }^{15}$ But now, to the extent that it is the noun it is used to qualify that determines the interpretation assigned to the adjective, it is only to be expected that it will not receive a different interpretation while it still qualifies that very same noun. ${ }^{16}$

${ }^{14}$ Of course, I'm restricting attention here to what we could call, vaguely enough, "natural" or ordinary readings of these sentences. In a situation in which one is paying particular attention to the fact that these terms may express different senses, one might perhaps interpret some of these sentences in a noncontradictory way; but, in that case, I take it, the same could be said about 'is' in a sentence such as (8), so that such readings would be dialectically innocuous.

15 I won't attempt to offer here an account of precisely how this accommodation of senses takes place; I assume it would be reasonable to suppose that it works very much like the phenomenon that Asher (2015) describes as coercion.

${ }^{16}$ In a previous version of this paper, I had used 'hard' as my favourite example of a polysemous term, as it seemed to me to fail all of these tests-in particular, it seemed to me that all sentences of the form of, say, 'This rock is hard, and it is not hard' were indeed contradictory. Then I was made to see that a sentence such as 'This book is hard, but it is not hard' might indeed receive a non-contradictory reading-namely, it may be used to affirm both that the text is very difficult to understand and also that the physical copy is apt to cause (physical) damage (but notice that in such a case the polysemy is double: both 'book' and 'hard' have different senses in those two readings). This should remind us (this is probably hardly needed) how difficult it is to be certain of a general negative existential claim (such as that there is no case of some specific sort), which is what the argument here (and also Pickel's own argument) requires. And so, even if I haven't found any example involving the term I now favour ('elastic') that could be naturally interpreted in a non-contradictory way, I am not in a position to assure that such an example could not be found. Thanks to Nahuel Recabarren for pressing me on this point. 
Now, it's interesting to notice in this connection that some terms that seem to behave very much like our examples 'hard' and 'elastic' above, at least in so far as we take into account their capacity to receive different interpretations, do seem to pass some of the tests for ambiguity Pickel uses. Consider (34) and (35):

(34) It's brilliant, but it's not brilliant.

(35) It's brilliant, and it's brilliant. ${ }^{17}$

Suppose now we are talking about Jeff Koons' Rabbit statue, a mirror-polished stainless steel sculpture with the form of a (stylized) rabbit. One might then be saying something non-contradictory with (34), and something non-redundant with (35). Now, what seems to be behind the availability of examples of this kind in connection with some terms but not with others does not seem to be so much their having different senses, and how those are connected with one another, but simply whether there are objects that could be described by different senses of the same term (something that, we have just seen, happens with 'brilliant' but not with 'elastic', even though it seems reasonable to assume that the two terms exhibit very similar semantic profiles). And, of course, the same happens more generally with regular cases of ambiguity: when the tests are positive (as with (34)), then we have evidence that the relevant clauses are ambiguous, or that they include polysemous terms; but a negative result (as with (31)) may be explained by different circumstances (the relevant terms being non-polysemous being only one of them).

On the other hand, as regards the syntactic tests for ambiguity, we find that few terms of the sort we are considering do pass the ellipsis and coordination tests. So, for instance, (36) and (37) seem perfectly proper, exhibiting no zeugmatic effect:

(36) Her ideas were brilliant; her jewellery too.

(37) His fists were strong; and so were his beliefs.

It follows then that terms such as 'brilliant' and 'strong' fail the ellipsis test, as they do not behave as ambiguous terms are expected to. And similar results seem to follow from the coordination test (again, (38) and (39) do not seem zeugmatic):

(38) Her ideas and her jewellery were brilliant.

(39) His fists and his beliefs were strong.

So we find that, on the one hand, different terms that seem to have rather similar patterns of polysemy (for instance, 'hard' and 'brilliant') behave differently as regards some of the tests, while some terms ('brilliant') are diagnosed as ambiguous according to one of them and as unambiguous according to others. Moreover, it would seem that differences in the "distance" between the relevant senses might also be revealed in the tests. ${ }^{18}$ Something of

17 'It's brilliant in all the senses of the term' would be an interesting, and in my view perfectly acceptable, variation on (35); thanks to Paula García Cherep for suggesting this example.

18 Some other perceived differences between the senses may not become apparent in the tests. So, for instance, even though it seems that the different senses of 'brilliant' in (36) and (38) are farther away than those of 'strong' in (37) and (39) (indeed, it could even be doubted whether we have two different senses in the latter case), they apparently pass the syntactic tests equally well. On the other hand, the distance may in some cases become great enough so as to give rise to zeugmatic effects. So, in a series of sentences analysed by Cruse (1982) (and also discussed by Geeraerts, 1993, pp. 244-5), we find 
that kind may be behind the circumstance that, whereas (40) and (41) seem acceptable (consider a case in which they appear in an advertisement for armoured doors), (42) seems zeugmatic, even though it seems to express something very close to what the two previous statements express:

(40) These doors are harder than reality.

(41) Reality is hard; and so are our doors.

?(42) Reality and these doors are hard. ${ }^{19}$

As this short discussion already shows, the situation is far from simple. Again, it would be beyond the scope of the present paper to try to give an overall diagnosis of what is going on in all these examples. But, in any case, it seems reasonable to me that an explanation of the different behaviour, in connection with the tests, of some of these terms might very well be connected with the fact that they typically express senses that partially overlap with one another, but that are also partially disjoint (in other words, they express sets of descriptive conditions that overlap, but only partially, with one another) ${ }^{20}$ So, for instance, the two uses of 'hard' in (27) and (28) seem to have some descriptive content in common, perhaps something like apt to cause damage, but they also express in each case traits not shared by both uses, such as resisting physical collisions, which is appropriate only for (28). Consistently with this image, as already hinted, it would seem natural to suppose that some of these different senses derive from one another (or from some common source) through pragmatic processes, such as for instance those of loosening, enrichment or transfer, as described by Recanati (2004). It's reasonable to suppose, besides, that the results of these operations might then become conventionalized to a greater or lesser degree, with the result that the different interpretations so obtained might then form a sort of chain, or perhaps better, a tree, of different, though related (and to different degrees overlapping) senses.

This image of how these terms work is highly tentative and metaphorical, of course, and I will not attempt to defend any specific proposal on the issue in what follows. But if something along these lines is on the right track, it could help us provide some illumination on the behaviour of these expressions. For instance, it seems reasonable to suppose that, while some of the tests, as we have been using them, classify some terms as ambiguous because they detect the existence of some differences among the senses they express (as with 'brilliant' in connection with the redundancy test), some of the other tests seem to classify instead a term as ambiguous on the basis of the existence of an important degree of dissimilarity between the different senses (and this is why 'brilliant', for instance, is not ambiguous according to the coordination test). The fact that this approach to polysemy could provide a reasonable account of these phenomena, difficult to account for from the perspective behind Sadock and Zwicky's tests, lends of course some limited support to the view.

that, though 'John likes blondes and racehorses' and 'John likes vintage port and marshmallows' are perfectly acceptable, 'John likes blondes and marshmallows' is zeugmatic, even though there is a chain of acceptable sentences of the same form going from the first to the second one, each of which derives from the previous one by replacing only one of the conjuncts at a time.

19 These examples are inspired in an actual advertisement, which includes sentence (40) almost verbatim.

${ }^{20}$ I do not mean to imply that the senses of content words should be understood in terms of a set of descriptive concepts or "characteristic marks"; I just make use of such an image for ease of exposition. 
These difficulties with the tests, moreover, add to some general misgivings already present in the literature as to their value for detecting terms receiving different interpretations. So, for instance, Geeraerts (1993) had already shown that the three classes of tests he recognizes (he also discusses some definitional tests besides those we mentioned above) give conflicting verdicts for some terms. And Norrick (1981, p. 115, discussed in Falkum and Vicente (2015, pp. 1-2)) also drew attention to the fact that small variations among otherwise very similar sentences may trigger different results (similar to what we have found concerning cases (40)-(42) above):

?(43) Judy's dissertation is thought provoking, though yellowed with age.

(44) Judy's dissertation is still thought provoking, though yellowed with age.

Notice first that the zeugmatic effect in (43) should make us think that 'dissertation' is ambiguous (namely, as between a sense in which it refers to an abstract type and another in which it refers to a concrete printed copy); but then the non-zeugmatic character of (44) should make as draw the opposite conclusion. This seems to point to the fact that there may be different sources of the zeugmatic effect in some such examples, and that therefore the test should be treated with some care.

Finally, I'd like to conclude this section by calling attention to the fact that, even though the terms usually characterized as polysemous very often express different senses as a result of their combination with other terms, the mechanism underlying such meaning shifts does not seem very different from the sort of mechanism underlying some cases of context-sensitivity - particularly those discussed by Pickel in this context (not all such cases, of course: cases of indexicality seem to be very different). Consider, for instance, 'Italian' as it appears in (45):

(45) Give me that Italian Book. ${ }^{21}$

What does 'Italian' mean here? It might express any of an indefinite range of properties: either having been made in Italy, or being written in Italian, or being about Italy, etc. Depending on what's relevant in a given context, the word, as used in that context, will express one or the other of these properties, but it will not be easy to get a non-contradictory reading of (46) unless a context shift (concerning which properties are relevant or salient in the context) takes place in the middle of the utterance:

(46) This book is Italian but it's not Italian.

We may get an intuitively non-contradictory reading of (44) if we had made salient, before the utterance, two different properties among the candidates to be designated by 'Italian'. This seems to be precisely what happens in Pickel's case (24) above: it seems that what allows us to obtain a non-contradictory reading of 'John's car is not John's car' (as in (24b)) is that the question in (24a) had made equally salient two different relations between John

${ }^{21}$ Notice, first, that this case is different from that of 'hard' we considered earlier, in that even the concatenation of 'Italian' with 'book' still leaves it indeterminate which property we mean by our use of 'Italian'; and also, second, that this term cannot be understood as a case of unspecificity (contra Sainsbury (2001)), as it seems natural to suppose that an utterer of (45) has a specific reading of 'Italian' in mind when she utters it (not any book that we might describe as Italian in some sense would satisfy her request). 
and the car (ownership and cleaning). Now, in connection with the hypothesis that 'is' may in some contexts express constitution, and the relevance of the ambiguity tests for assessing that possibility, we should first note that, as we already remarked, from the fact that an expression may receive different interpretations in different contexts it doesn't follow that we could always build a context in which different instances of the term receive different interpretations, which would enable us to detect the ambiguity by using the tests. The fact that this may happen in some cases, as in (24), should not make us expect that this would happen whenever we have context-sensitive terms. Even so, I suspect that, if we avail ourselves of the resources Pickel makes use of in building an appropriate context for (24), we could also build contexts in which, say, both constitution and predication are salient, so that (8) above (here repeated) would be acceptable (imagine a context in which both the contrast between statues made of clay and of some other material, on the one hand, and another one between statues and "mere" pieces of clay, were salient): ${ }^{22}$

(8) The statue is a piece of clay, but it is not a piece of clay. ${ }^{23}$

To conclude this section, then, it seems that the existence of polysemous and (some kinds of) context-sensitive words, in particular words whose interpretations cannot be made to vary easily, either because they depend on (relatively) rigid features of (non-linguistic) context, or on the terms the terms combine with, pose some limits to the argumentative strategy deployed by Pickel. In particular, if our suggestions in this section are correct, it seems that it doesn't follow from the fact that we may be unable to detect different senses through the ambiguity tests that the terms do not in fact express different senses.

\section{3. 'IS' AS POLYSEMOUS}

The argument of the previous section has been rather general: if we are on the right track, the fact that some terms, such as 'elastic' or 'hard', do not pass (many of) the tests for ambiguity, is not necessarily evidence of those terms being monosemous ('elastic' presumably is not so). Now, I think that we could go beyond this purely negative argument, and argue positively that there are good reasons to think that there is an 'is' of constitution, given that 'is' seems to behave very much (though not always exactly) like polysemic words such as 'elastic' and some of the other examples we discussed above. I'll try to give reasons in favour of this suggestion in the remainder of this paper.

In what follows I'll focus mainly on cases of relational 'is', namely, on cases in which 'is' appears in sentences of the form ' $a$ is $b$ ' (or ' $a=b$ '), such as (5) and (6) above, where ' $a$ ' and

22 One such context might be the following: suppose we are in an art school, and that after a sculpture class the janitor and his/her assistant are required to put clay statues on a shelf, discarded ones (now taken as mere pieces of clay) on a drawer, wax statues in a different shelf, and mere pieces of wax in another. One of them may be uncertain about a particular piece, and might then ask the other whether it is a piece of clay. The other may then answer: "That's a piece of clay, but it's not a piece of clay".

23 I mention these examples involving (non-linguistic)-context-dependence in part because Pickel discusses them, but also because they allow me to highlight how similarly they behave to other cases of semantic variability, which in turn seems to suggest that many of these phenomena involving semantic variability might very well be understood as just so many cases that occupy different positions in a single spectrum (a suggestion I will not (and indeed, cannot) try to substantiate here). 
' $b$ ' are singular terms. ${ }^{24}$ I do so for (at least) two reasons: first, because this is the sort of case in connection with which Wiggins originally discussed the hypothesis that there is an 'is' of constitution; and also because the formal analysis of these cases seems less controversial than the analysis of cases such as (4) (as it is unclear whether 'is' is relational or predicative in such a sentence). Now, even if we leave aside cases where 'is' has been thought to express constitution, it seems that there are many statements formally similar to (5) and (6) where 'is' could hardly be understood as standing for identity. Consider the following cases:

(47) Bill Bixby is The Magician (as in the opening of the classic TV series).

(48) I am this one (pointing at a counter in a board game).

(49) This is the Queen (pointing at a sugar cube on a chess board; cf. Wiggins (1980, p. 43)).

(50) Haddad is Lula (as in recent political advertisements in Brazil).

(51) Tell him, finally, I have found that to be a Roman is to be a brute. Farewell. (Lew Wallace, Ben Hur).

(52) And as to being loyal, what is that? It is being truthful! It is being faithful! (Joseph Conrad, The Arrow of Gold; for the last two examples cf. Schnieder (2005, p. 230)).

It seems clear to me that 'is' in (47)-(52) does not express strict identity-nor does it there express constitution either. Examples such as (47) and (49) have been described by Wiggins as examples of an "is' of representation" (and (48) probably belongs to this class also), while the examples (51) and (52) have been discussed by Benjamin Schnieder under the label "is' of involvement"-because, for instance, what (51) seems to express is that being Roman involves being brute..$^{25}$

${ }^{24}$ I leave aside complications arising from the circumstance that, on some views, definite descriptions are not singular terms; nothing of importance depends on this.

25 I have been asked (also by an anonymous referee for this journal) whether it would not be possible to give a pragmatic account of the acceptability of (47)-(52), and whether this would undermine (or not) my argument here. I don't want to deny that a pragmatic explanation of some of the phenomena involved could be given - although I also think that, even if one might reasonably assume that a pragmatic process has been involved in the initial acceptable uses of sentences of these forms with the relevant non-literal meanings, these meanings seem now to have become (at least to an important degree) conventionalized. Be that as it may, I don't see how the availability of such an explanation could favour the Monist. This is because the only pragmatic explanation of how (47)-(52) might end up expressing the relevant non-literal meanings I can think of would be similar to Grice's explanation of metaphor (cf. Grice, 1989, p. 34); and, even if this account in fact requires that we understand 'is', as it appears in those examples, as an 'is' of identity, it also requires that the statements so construed should be blatantly false. This is obviously not grist to the mill of the Monist, who needs the identity to be literally true. On the other hand, I don't find Pickel's reasons for his view that the Pluralist cannot accept a pragmatic explanation compelling-in fact, I'm not sure I understand what his reasons are. He says that such an explanation "would mean the speakers were not speaking literally when they uttered [sentences such as (4)-(6)]", which "would put the pluralist in an awkward position, as the arguments for pluralism often rely heavily on speakers' intuition [of] their ordinary judgments" (p. 199). There are at least two problems with this: on the one hand, Pluralists' involvement with cases such as (4)-(6) is rather defensive, only directed at providing an explanation of their intuitive acceptability compatible with their main claims-claims that are not supposed to be grounded on our evaluation of those state- 
Now, just like 'hard', 'brilliant' and other similar terms we discussed above, it would seem that 'is' expresses different senses in (some of) these different examples; and, just as in those cases, it also seems that these different senses are not completely unrelated (perhaps something like interchangeable with-or equivalent to... for the purpose at hand might be suitable candidates for expressing what all those senses of 'is' have in common, although I won't try to defend any specific proposal on this issue).

On the other hand, these different uses of 'is' also seem to get mixed results with the ambiguity tests. In fact, it seems unclear to me whether any of (47)-(52) passes the contradiction test. For instance, (53) and (54) seem contradictory, and no similar example that comes to mind appears to have a non-contradictory reading, while (55) is rather doubtful to me (perhaps suggesting, then, that (49) may be an exception):

* (53) To be Roman is to be a brute, and it is not to be a brute.

* (54) I am this one, but I'm not this one.

? (55) This is the Queen, and it is not the Queen. ${ }^{26}$

And we obtain an even clearer result with the other semantic test, the one focusing on redundancy. Indeed, all of (47)-(52) seem to give rise to redundant conjunctions, as for instance (56) and (57) seem to show:

* (56) Haddad is Lula, and he is Lula.

* (57) To be Roman is to be a brute, and to be a brute.

The situation as regards the coordination tests seems more difficult to assess. We saw above that Pickel often argues from the non-zeugmatic character of some sentences to the unambiguous character of some of the terms involved-if, for instance, there is some reason to expect the sentences to give rise to zeugma whenever we suspect the relevant terms to be ambiguous (see, for instance, how he argues for the unambiguous character of 'is' on the basis of the nonzeugmatic character of (20) above, and my discussion of his methodology in fn. 8 and 9). In so far as that way of arguing is acceptable, then (58) and (59), for instance, may be seen as providing evidence for 'is' being unambiguous there, as both of them seem non-zeugmatic:

(58) This is the Queen, and the sweetest object on the chess board. ${ }^{27}$

(59) Being loyal is being truthful, and the virtue you most conspicuously lack.

ments; on the other hand, there's nothing in the notion of 'intuitive acceptability', it seems to me, that should require a specifically semantic explanation of the phenomenon.

26 What seems to be going on in this case (and apparently also in cases corresponding to examples such as (47) and (50) above) is that once one interpretation of 'is' has been adopted in a given context, it seems rather difficult to induce a different one. Besides, it seems to me that, to the extent that different interpretations could be given of 'is' in these cases, the same would happen in cases where the 'is' of constitution is involved (for instance, if someone argued that we could perhaps felicitously (i.e., non-contradictorily) assert 'Haddad is Lula, but he is not Lula', if we had a context in which both the relations of identity and representation had been made salient, we could respond that the same could happen with 'Goliath is Lumpl, but it is not Lumpl', provided both identity and constitution had been made salient in the context in which it is uttered; cf. the discussion of (8) in fn. 22).

27 It has been argued (Fara, 2001) that definite descriptions after 'is' (and even in general, but the arguments for this are less convincing to me) should be understood as predicates. I tend to agree with this view, but I will ignore it in what follows for simplicity. I take it, then, that in the following examples the definite descriptions always behave as singular terms. 
But some other examples provide evidence against this conclusion. Consider for instance an acting class, in which Amy does not know that Mary Jo is the same person as Mary, and Ben informs her of that; and that in the same situation roles are being distributed for a play, and Mary is given the role of Beth in an adaptation of Little Women for the stage. ${ }^{28}$ In such a case, even if (60) and (61) are acceptable, (62) seems zeugmatic-which would suggest that 'is' is being used with different senses in the two previous statements:

(60) Mary Jo is Mary.

(61) Mary Jo is Beth.

*(62) Mary Jo is Mary and Beth.

We find, then, that the tests give conflicting results in connection with all these arguably distinct senses of 'is'. In these cases, then, 'is' seems to behave, as regards the tests, just like other polysemous words such as 'hard' or 'brilliant'. And it also behaves very much like alleged cases of the 'is' of constitution. In this connection, I tend to think that (63) is as contradictory as (53) or (54), and that (64) is more zeugmatic, if anything, than (58) or (59):

(63) Goliath is Lumpl, but it is not Lumpl.

?(64) Goliath is Lumpl, and the best cubist sculpture in the country. ${ }^{29}$

Moreover, (65) is a case very similar to the zeugmatic (62), but where 'is' arguably expresses constitution:

*(65) The Mona Lisa is this tiny chunk of wood and oil painting, and La Gioconda.

It would seem to follow from the discussion above, then, that cases where 'is' might naturally be taken to express constitution, and cases where it expresses some of the other senses of 'is' recognized in the literature, behave very similarly as regards the ambiguity tests. And it is also important to stress, moreover, that if Pickel's arguments were indeed successful in showing that there is no 'is' of constitution, then it should follow, by parity of reasoning, that 'is' could not be taken to express anything other than strict identity in all of (47)-(52). But such a view seems to me difficult to accept. Indeed, it seems to me a non-starter to suppose that being a Roman is identical (i.e., is the same property as) being a brute; or to suppose that I am identical with a counter. And, besides, cases such as (65) seem to provide direct evidence for the existence of a distinct 'is' of constitution.

I take it, then, that if what has been said so far is on the right track, then Pickel's arguments are unable to undermine the view that, in statements such as (5) or (6), 'is' expresses the relation of constitution.

Now, what happens with those cases where it is the predicational 'is' which (allegedly) expresses constitution, as in our initial example (4)?

(4) The statue is a lump of clay.

28 This situation is based on one discussed by an anonymous referee.

29 The results regarding these cases are, of course, in line with Pickel's own views; I mention (64) only at this stage of the argument because Pickel did not explicitly discuss statements of this form (i.e., of the ' $a=b$ ' form, with 'is' allegedly expressing constitution) when presenting his views. 
After all, this is the example that Pickel mostly discusses. If we thought that in such cases what we do is to identify "an object named" with "an object ambiguously described", as Russell did (1919, p. 172), then we might try to adapt the account given above for relational 'is' to cases of this kind - after all, this view would amount to saying that all such cases also involve a relational 'is'. So that we could say that, in cases such as (4), we are not identifying "an object named" with "an object ambiguously described", but, instead, indicating that they are related through constitution. It would be nice if things were like that, as that would make our work easier. But, unfortunately, I don't think that such an account is correct. It seems to me, on the contrary, that 'is', as it appears in (4), is not the 'is' of identity, but the 'is' of predication, the same that appears in (66):

(66) The statue is shiny.

As I said, I think that (4) neither expresses, nor commits us to, the claim that the statue is identical to (that is, that it is itself) a lump of clay. How should an account of what happens with 'is' in cases such as this one look like, in order to allow us to obtain this result? I will not try to offer here a full account of what's going on in these cases-I really don't have any such detailed account. But I will try and suggest very tentatively some ideas about how we could go about explaining what's going on in these cases.

Here is the suggestion: sortal terms, and noun phrases built on their basis, seem to be associated with (at least) two kinds of conditions, those that Thomasson (2007, in particular pp. 39-42 and 55-59) called their "application" and "coapplication conditions". 'Statue', say, would then be associated with conditions of application (some set of properties that have to be present in some situation (or region of space-time) for the term to apply correctly to it (or what is located there)) and also with some conditions of coapplication (namely, a specification of the circumstances that have to obtain for us to be able to say that, for instance, something to which the term applies is the same thing as what appears in some other region or situation and to which it also applies). Now, we have already found that, in different (linguistic) contexts, some terms might end up expressing only a subset of the traits or descriptive conditions that they encode. So, for instance, when 'hard' combines with 'remark' it expresses some descriptive conditions, but it expresses some different ones when it is combined with, say, 'rock' - that is, a sort of accommodation takes place, so as to avoid inconsistencies or inappropriateness in the interpretation of the whole sentence. Now, it seems to me that something similar goes on with sortal phrases in predicative position.

Consider now again a case like (4). In this statement, we use 'the statue' to identify a certain material object, and we exploit, when we do that, the application and coapplication conditions associated with 'statue', which help us delimit the object we want to refer to by expressing its persistence and individuation conditions (this is a point that Strawson highlighted, in connection with what he describes as "conventions for referring expressions"; cf. Strawson, 1950, 1959). Now, what happens when we say, of that statue, that it also "is a lump of clay"? It is usually assumed that 'lump of clay' is also associated with its own persistence and individuation conditions and, in particular, with persistence and individuation conditions different from (incompatible with) those associated with 'statue'. Are we then also attributing to the statue these other persistence and individuation conditions? That would be inconsistent! I think it would be a reasonable hypothesis to suppose that, to avoid an eventual clash in the criteria of individuation we are attributing to what we are talking 
about, the sortal term in the predicate might just drop the coapplication conditions it expresses, so that in such contexts it just expresses its application conditions (just as 'school' drops its trait institution, but retains building, when combined with 'to build' in a sentence such as 'My school was built in 1848'). If this suggestion is correct, then what (4) would express is that the statue has the qualitative, physical, "non-sortalish" properties of a lump of clay, something that comes very close to expressing that the statue is constituted by a lump of clay (cf. Bennett (2004) for a discussion of "non-sortalish properties").

I don't pretend to have offered here anything more than just a very preliminary suggestion for dealing with these cases. The elaboration of an adequate treatment of them will have to be left for future work. In the meantime, I hope I have provided good reasons for thinking that the proposal that there is an 'is' of constitution, at least for the relational cases originally discussed by Wiggins, remains unaffected by Pickel's arguments.

\section{Acknowledgments}

I would like to thank Axel Barceló, Delia Belleri, Eduarda Calado, Ramiro Caso, Lenny Clapp, Robert Garcia, Paula García Cherep, Dan Korman, Eleonora Orlando, Bryan Pickel, Stefano Predelli, Nahuel Recabarren, Gonzalo Rodriguez-Pereyra, Marco Ruffino, Andrés Saab, Agustín Vicente and two anonymous referees for suggestions and comments on earlier versions of this paper, and/or for discussion on topics connected with it. The research leading to this paper has been partly funded by the Ministry of Science and Innovation (Government of Spain) and the European Union (grant number PID2019106420GA-100/AEI/10.13039/501100011033) and the National Agency for the Promotion of Research, Technological Development and Innovation (Argentina, grant number PICT 2016-2128).

\section{REFERENCES}

Asher, N. (2015). Types, meanings and coercions in lexical semantics. Lingua, 157, 66-82.

Bennett, K. (2004). Spatio-temporal coincidence and the grounding problem. Philosophical Studies, 118, 339-71.

Cruse, D. (1982). On lexical ambiguity. Nottingham Linguistic Circular, 11, 65-80.

Falkum, I. and Vicente, A. (2015). Polysemy: Current perspectives and approaches. Lingua, 157, 1-16.

Fara, D. (2001). Descriptions as predicates. Philosophical Studies, 102, 1-42 (originally published under the name D. Graff).

Fine, K. (2003). The non-identity of a material thing and its matter. Mind, 112, 195-234.

Geeraerts, D. (1993). Vagueness's puzzles, polysemy's vagaries. Cognitive Linguistics, 4, 223-72.

Gibbard, A. (1975). Contingent identity. Journal of Philosophical Logic, 4, 187-222.

Grice, P. (1989) Studies in the way of words. Cambridge (MA): Harvard University Press.

King, J. (2006). Semantics for monists. Mind, 115, 1023-58.

Korman, D. (2015). Objects. Nothing out of the ordinary. Oxford: Oxford University Press.

Noonan, H. (1993). Constitution is identity. Mind, 102, 133-46.

Norrick, N. (1981). Semiotic principles in semantic theory. Amsterdam: John Benjamins.

Nunberg, G. (1979). The non-uniqueness of semantic solutions: Polysemy. Linguistics and Philosophy, 3, $143-84$. 
Pickel, B. (2010). There is no 'is' of constitution. Philosophical Studies, 147, 193-211.

Quine, W. (1948). On what there is. Reprinted in W. Quine, From a logical point of view. New York: Harper, 1963.

Quine, W. (1960). Word and object. Cambridge (MA): MIT Press.

Recanati, F. (2004). Literal meaning. Cambridge: Cambridge University Press.

Russell, B. (1919). Introduction to mathematical philosophy (1993 reprint). New York: Dover.

Sadock, J. and Zwicky, A. (1975). Ambiguity tests and how to fail them. In J. Kimball (ed.). Syntax and semantics, Vol. 4 (pp. 1-36). New York: Academic Press.

Sainsbury, R. M. (2001). Two ways to smoke a cigarette. Ratio, 14, 386-406.

Schnieder, B. (2005). Property designators, predicates and rigidity. Philosophical Studies, 122, 227-41.

Strawson, P. (1950). On referring. Mind, 59, 320-44.

Strawson, P. (1959). Individuals. London: Methuen.

Thomasson, A. (2007). Ordinary objects. Oxford: Oxford University Press.

Vicente, A. (2018). Polysemy and word meaning: An account of lexical meaning for different kinds of content words. Philosophical Studies, 175, 947-68.

Wiggins, D. (1980). Sameness and substance. Oxford: Blackwell.

Ezequiel Zerbudis has a PhD in Philosophy from the Universidad de Buenos Aires, currently teaches Metaphysics and Philosophy of Language at the Universidad Nacional del Litoral (Santa Fe, Argentina) and the Universidad Nacional de Rosario (Rosario, Argentina), and also has a research position at the CONICET (the National Research Council of Argentina). His research focuses now mainly on the metaphysics of material objects, but he is also interested in some more general metaphysical issues (properties, particulars, individuation, free will) and their history, as well as in the relation between metaphysics and the philosophy of language.

Address: Instituto de Filosofía, Universidad de Buenos Aires, Puán 480 (1406) Ciudad de Buenos Aires, Argentina. E-mail: ezerbu@yahoo.com https://orcid.org/0000-0002-0093-372X 